\title{
Future Vision
}

\author{
Simon Rogerson
}

\section{Abstract}

\section{Purpose}

This paper reviews the world of ICT from its early days to the near future. The aim is to consider how successfully academia, industry and government have worked together in delivering ethically acceptable ICT which is accessible to those who might benefit from such advances. The paper concludes with suggestions of a fresh approach for the future.

\section{Design/methodology/approach}

The paper draws upon evidence from the history of computers, funded research projects, professional bodies in the field, the ETHICOMP conference series and reported ICT disasters. The author uses his experience as both an ICT practitioner and an academic in the ICT ethics field to synthesise the evidence so providing a foundation on which to build an outline global action plan.

\section{Finding}

The paper lays out the findings that there has been much detailed observation and analysis of the ethical challenges surrounding ICT but the transformation of this into widespread practical positive action remains elusive. It explores why progress has been difficult.

\section{Originality/value}

This review of the interconnecting landscapes of practical ICT, funded research and the ICT ethics community is new. The attempt to demonstrate what progress has been made and to identify the underlying factors which influence progress are valuable to future generations working in this area. The concluding suggestions for action offer a starting point for entering the next phase of ICT ethics.

\section{Keywords}

ICT, ethics, ETHICOMP, history of computers, professionalism, millennials, top-down, middle-out, bottom-up, five minds, ITNOW, haiku

\section{Paper Type}

Viewpoint

\section{Introduction}

\author{
Now social networks \\ Before tea-room social chat - \\ IT changes us ${ }^{1}$
}

Founded in 1884, J. Lyons \& Co. was a market leader in the UK for fine teas and cakes. In 1894 it opened a teashop in Piccadilly, London and developed this into a chain of over 200 teashops known as Lyon's Corner Houses. In 1951, it built and programmed its own computer, LEO 1 which was used to manage the daily restocking of the Lyon's Corner Houses (Ferry, 2003). It was the first company worldwide to use a digital computer in a commercial setting and heralded the start of business data processing. Similarly, this commercialisation of computing was the beginning of the IT profession which today spans the world in terms of application reach and social impact.

\footnotetext{
${ }^{1}$ The Japanese Haiku is a way of looking at the world and seeing something deeper. In English a haiku poem consists of three lines, with the first and last line having 5 syllables, and the middle line has 7 syllables. The use of punctuation such as a dash divides the poem and prompts the reader to reflect on the relationship between the two parts. The inclusion of three Haiku poems in this paper serves to illustrate the value of crossdisciplinarity in analysing situations. Readers of this paper are encouraged to reflect on the deeper meaning of each haiku and use this in their Future Vision. Together the three Haikus form a poem entitled Technological Dependency (Rogerson, 2015).
} 
In 1972, I entered the IT profession as a newly-qualified graduate. By that time IT was well established as a vital corporate resource supporting all aspects of business. However it was still a back-office function staffed by specialist technologists with little experience of business. Fast forward to 2015 and we find that IT (or commonly termed ICT in recent times) now pervades almost every human activity. It no longer is restricted to scientific or commercial endeavour that typified the era of the 1970s. It is a very different world from 64 years ago and the age of LEO. Those entering the ICT profession today are faced with a plethora of application areas using a vast array of technological armoury. Not only that, but ICT has been democratised to the extent that many applications are built by non-ICT professionals.

In common with most ICT practitioners, I worked on many systems, some of which failed. Failed ICT systems are still commonplace. Here are just three of the many headline-grabbing failures of recent years. In 2002, a project was launched to upgrade NHS computer systems in England with the aim of revolutionising the way technology is used in the health service through electronic records, digital scanning and integrated ICT systems across hospitals and community care. The project was scrapped in 2011 due to technical and contractual problems at a cost of around f10bn. In 2014, Royal Bank of Scotland was fined $f 56 \mathrm{~m}$ by the UK's financial regulators for a system crash which left millions of customers unable to make or receive payments. In 2012, the collapse of an ICT system at a border agency office prevented the processing of thousands of visa applications for foreigners in the UK. The system was used to issue non-EU nationals with a mandatory biometric residence visa or permit.

It was the issue of system failure which led to my involvement in ICT ethics. My industrial career spanned programming, systems analysis, project management and IT services management. Sharing this experience with my students made me realise that current practice of the time was having little effect on reducing the risk of system failure. It seemed practitioners were too close to the technological problem. By moving further away, other issues started to become visible - social and ethical issues which at that time were not within the remit of the ICT professional. I discovered the work of Deborah Johnson, Jim Moor, Don Gotterbarn, Chuck Huff and Terry Bynum in the fledgling field of Computer Ethics. The opportunity of working with non-ICT disciplines to address the issue of system failure seemed to offer a solution to this problem which had dogged ICT from the onset of business data processing.

It was this change in my approach which eventually led to the creation of the Centre for Computing and Social Responsibility, ETHICOMP and the Journal of Information, Communication and Ethics in Society. All three have made significant contributions to the development of a thriving international ICT ethics community over the last 20 years. In 1995, when ETHICOMP was launched, the world had become ICT-dependent. The conference brought together a worldwide community of scholars from many disciplines and backgrounds, who were worried about the lack of understanding or concern of the impacts of Information and Communication Technologies (ICT) on individuals and the world at large. At the time the Times Higher reported that at ETHICOMP 95 (THES, 1995), “...Delegates from 14 countries agreed in principle to set up a global network of centres to develop the debate and provide information on socially responsible computing. ... Besides core ethical issues such as privacy, fraud and obscenity, the researchers will examine broader issues of social responsibility, including the devaluing of jobs and the possible emergence of a gulf between information haves and have-nots."

Two decades later it is time to look forward once more. How much have we learnt anything about the manner in which ICT is created, developed and applied? How much have academia, industry and government come together to address effectively the wider implications of an increasingly technologically-dependent world? Sadly, on balance the answer to both questions seems to be very little. There has been much detailed observation and analysis but still the transformation of this into widespread practical positive action remains elusive. In this paper I delve beneath these two questions to try to understand why progress has been difficult. The paper concludes with suggestions of a future approach. 


\section{An ethics progress litmus test}

BCS, the Chartered Institute for IT, ran a special edition of ITNOW in the autumn of 2014 which focused on Ethics in ICT. In many ways it is a litmus test of ethics progress by academics and practitioners working in tandem. It is a disappointing read.

Runciman (2014) points out the "philosophical challenges of extraordinary complexity" in the US Navy's pursuit of embedding moral competence in computational architecture of warfare technology. This project smacks of arrogant technological determinism which is so dangerous. The discussion by Bennett (2014) on robot identity assurance concludes with a series of uninspiring recycled actions. For example, "debate about the use of RFID and NFC technologies which enable tracking of individuals without their knowledge or consent." was an action called for many years ago (for example, see Rogerson (2004)).

Southey (2014) discusses the every-increasing scope of ICT application. He concludes, "The ethical dilemma that faces us is therefore: can I justify unleashing this IT development, knowing that I do not know the extent of its safety? Have I even come close to imagining the worst that could happen? Of course, we can argue, the IT profession is not regulated like law or medicine; BCS has a voice but, unfortunately, no real clout. If we refused to work on robot soldiers, someone else will do it." Once again he simply restates observations of the past. The same is true of Dainow (2014) who discusses the ethics of emerging technology. He concludes, "The IT professional is moving to join the doctor at the centre of modern ethical concerns for society. Society's gaze is sure to follow. It is no longer viable for IT professionals to remain ethically neutral. The next generation of technology will inevitably generate more controversy and concern than anything seen so far. We have enough experience to anticipate many of the issues and avoid them through conscientious and ethically aware design."

Cultural diversity is explored by Freeland (2014). He concludes by highlighting gender discrimination as a key issue in ICT application. This has been known about and investigated for over 20 years. Freeland's article seems naïve and shallow. Holt (2014) focusses on the issue of ethically fit-for-purpose. Once again her conclusions are disappointingly lacking in new insight when she writes "... as IT professionals we have a duty to build a mind-set of considering the wider consequences of the IT solutions our developers design ... we need to contribute to the wider debate of how IT solutions are used, and how ethical decisions are made around IT-enabled concepts. ... So finally, let's get our professional bodies involved in leading the way to develop policy and opinion pieces before our politicians enforce laws, or our judges pronounce life-changing judgments that result in even greater ethical issues." Twenty years ago I wrote (Rogerson, 1995), “... no longer can the profession seek absolution through focusing only on the technical agenda. Indeed, the first question any IS/IT professional should ask is 'Is the action ethical?' and be able to answer based on reasoned thought. - We all need to act and act now!" It is disheartening to find Holt writing similar statements in 2014.

Overall, it is a disappointing edition of ITNOW. The lack of ethical consideration in systems design and implementation is evident. The calls for action are neither new nor inspiring. There is virtually no evidence and no pragmatic action; the emphasis being on top-down political rhetoric. In many ways this edition illustrates at best that we have stood still but probably we are moving backwards in the quest for ethically-acceptable technological implementations. There is little evidence of drawing from more than 20 years of effort in developing ICT ethics thinking and practical approaches. Even more surprising is that there is no mention or use of past BCS efforts in addressing ethics (for example, see Harris et al (2011)).

In 1995, Terry Bynum and I wrote (Rogerson and Bynum, 1995), "The brave new world of the information society - with its robots and global nets, telemedicine and teleworking, interactive multimedia and virtual reality - will inevitably generate a wide variety of social, political, and ethical questions. What will happen to human relationships and the community when most human activities are carried on in cyberspace from one's home? Whose laws will apply in cyberspace when 
hundreds of countries are incorporated into the global network? Will the poor be disenfranchised cut off from job opportunities, education, entertainment, medical care, shopping, voting - because they cannot afford a connection to the global information network? These and many more questions urgently need the attention of governments, businesses, educational institutions, public advocates and private individuals. We ignore ethics and computing at our peril." The evidence from the ITNOW special edition suggests our warnings are yet to be heeded.

\section{The evolving landscape}

The evolving ICT landscape is complex and diverse. Technological advances increase the pervasiveness of application to the point where ICT seeps into all aspects of our lives. That in turn causes social turmoil and even ethical questioning. It is this landscape which has been the centre of attention for the ETHICOMP conference series for twenty years. The nature of this changing landscape is vividly illustrated by the themes of the ETHICOMP conferences.

After the generic call for papers for the first conference, ETHCOMP 95, each succeeding conference had an overall theme which reflected current topics of concern. ETHICOMP 96 had the theme "The value of IT to society and the likely impacts upon society's values". It covered areas such as: organisation and society structure and the location of work; privacy and monitoring; value and accuracy of data and information; software and data as intellectual property; security and computer misuse; and developing information systems now and in the future. Many, if not all, of these topics remain of concern and form part of the current landscape.

The theme of ETHICOMP 98 was "Computing and the workplace; the potential tension between financial goals, politics and personal agendas; and social and professional responsibility". Whilst the perspective was different the detailed areas of concern were similar to ETHICOMP 96. By ETHICOMP 99 the concerns over pervasion were evident. The conference theme was "Look to the future of the Information Society". The aim was to focus on how achievements of the past could be built upon to ensure that the important issues impacting upon society, its citizens and its organisations would be effectively addressed and so help improve the quality of life.

The concept of the Information Society had firmly been established and ETHICOMP 2001 reflected this in its theme "Systems of the Information Society". The aim was to focus on the ethical and social impacts of systems on society, organisations and individuals. This was done from four perspectives: software engineering and systems development; teaching ethics to computing students; ethics in virtual communities; and ethics in the off-line world. Concerns for the individual increased and ETHICOMP 2004 focused on "Challenges for the Citizen of the Information Society". The aim was to consider the social and ethical impact of ICT on individuals as consumers, as employees and as citizens.

ETHICOMP 2007 had the overall theme of "Glocalisation: Bridging the Global Nature of Information and Communication Technology and the Local Nature of Human Beings". The aim was to explore the global nature of ICT and the associated local as well as global challenges. Such challenges existed, for example, in eDemocracy, assistive technology, nanotechnology, technologyenhanced learning, and health informatics. This global focus honed in on social media at ETHICOMP 2011 with the theme "The social impact of social computing" covering applications, technological infrastructure and theoretical underpinnings. Wang et al (2007 p79) explain, "With the advance of Internet and Web technologies, the increasing accessibility of computing resources and mobile devices, the prevalence of rich media contents, and the ensuing social, economic, and cultural changes, computing technology and applications have evolved quickly over the past decade. They now go beyond personal computing, facilitating collaboration and social interactions in general. As such, social computing, a new paradigm of computing and technology development, has become a central theme across a number of information and communication technology (ICT) fields. It has become a hot topic attracting broad interest from not only researchers but also technologists, software and online game vendors, Web entrepreneurs, business strategists, political analysts, and digital government practitioners, to name a few." This illustrates the point made in the call for 
papers for ETHICOMP 2015 that "many of the concerns of 1995 have deepened and many new ones have arisen". Thus the landscape continues to evolve dramatically.

\section{Drivers}

This evolving landscape is formed by the interaction of a set of drivers. There are top-down drivers which are typically impositions by bodies of authority which dictate where resources should be placed to achieve some overall goal. Bottom-up drivers emanate typically from grassroots collectiveaction resulting in a widespread change. Middle-out drivers involve all those within, for example an organisation, who are empowered to initiate change, support it, propose new ideas, and innovate. Middle-out drivers do not exhibit the hierarchal characteristics which the top-down and bottom-up drivers do. Boyle (2009) suggests top-down drivers provide political direction, middle-out drivers are the focus of change teams and bottom-up drivers are the voice of citizens. Three key drivers are now considered.

\section{Bottom-up}

Millennials are those currently in their late teens to early 30 s and within five years they will constitute half of the workforce (Frey and Berger, 2014 and Ericsson ConsumerLab, 2013). They are a bottom-up driver because they, as citizens, have grown up with technology and consider change as ever-present. Three quotations typify millennial perception:

"For Millennials, technology is a sixth sense. It's a way of knowing the world. There is no real cognitive processing like there is for other generations who learn it later in life."

"They are very, very comfortable with change. They have a global awareness, they are very resilient, and they are technologically very savvy, creative and collaborative."

"When Millennials become managers, I think there will be zero tolerance for inefficient systems in technology. They already don't understand the legacy systems."

(Ericsson ConsumerLab, 2013, p.8, p10, p11)

Increasingly millennials will influence the way in which society looks at technology, what is acceptable technology and what is not. The demand for more flexible working and the blurring of traditional boundaries between home and work will increase. The millennial voice will be heard and will have to be taken into account.

\section{Middle-out}

The ICT Relationship trinity is a middle-out driver concerning the delivery of ICT. The identification, development and use of ICT occur within a set of interrelated entities. These entities are defined in three sets: vendors of both hardware and software; developers of both infrastructure and application; and direct and indirect recipients of ICT. Relationships exist between this trinity of entity sets. If the trinity operates effectively then the likelihood of acceptable ICT is increased (Rogerson, 2014). The ICT relationship trinity will both be affected by and affect organisational culture, business strategy and societal norms.

Trust across the trinity is paramount. Smith (2011) explains that trust is a social relationship where ' $A$ ' trusts ' $B$ ' to do ' $C$. ' $A$ ' will only trust ' $B$ ' if ' $A$ ' believes ' $B$ ' to be trustworthy with respect to ' $C$ ' and for ' $B$ ' to be trustworthy requires that ' $B$ ' has both the competence and the motivation to satisfy the requirements of ' $C$ '. Smith (2011) suggests that trust is relational in nature and this implies that trustworthiness is but one component of a larger social relationship of trust between actors in this case across the ICT relationship trinity. 
Consider this example. In the delivery of a graphical user interface operating system (GUIOS), an application software developer will only trust a vendor if the developer believes that the vendor is trustworthy with respect to GUI-OS and for the vendor to be trustworthy requires that the vendor has both the competence and the motivation to satisfy the requirements of providing a robust GUI-OS. Similarly, a user recipient will only trust a developer if the user recipient believes that the developer is trustworthy with respect to the application and for the developer to be trustworthy requires that the developer has both the competence and the motivation to specify and produce acceptable application software. Paradoxically, in the larger social relationship of trust, a recipient may distrust a developer to deliver new software because either competence or motivation or both are lacking but at the same time might trust the same developer regarding ongoing maintenance of existing software because both competence and motivation are present. This example illustrates the complex and dynamic nature of the ICT relationship trinity and the how its success drives acceptable ICT and its failure leads to unacceptable ICT.

\section{Top-down}

As mentioned earlier, top-down drivers provide political direction. Therefore, high level policies are top-down drivers. Within the European Union the research and innovation frameworks direct enormous effort in, for example, ICT development and application. Horizon 2020 (H2020) is EU Research and Innovation programme with nearly $€ 80$ billion of funding available over 7 years (2014 to 2020). It aims to drive economic growth and create jobs. The claim is that, "It promises more breakthroughs, discoveries and world-firsts by taking great ideas from the lab to the market." There are three perspectives in H2020: social challenges; creating industrial leadership and competitive frameworks; and excellence in the science base. ICT is pervasive within these perspectives (European Commission, 2013). The stated aims and objectives show the political steer of $\mathrm{H} 2020$.

In the following example, ICT-related activity is considered (European Commission, 2014). In practice, Responsible Research and Innovation (RRI) has five different aims:

- engaging society more broadly with research and innovation activities (public engagement),

- facilitating the access to scientific results (open access),

- ensuring gender equality in both the research process and research content (gender dimension),

- taking account of the ethical dimension (ethical issues), and

- promoting formal and informal science education (education).

In contrast, Social Sciences and Humanities (SSH) are expected to provide a rich contribution to research and innovation, in at least two ways:

- Monitor economic, legal, and social issues related to technological developments. Furthermore, explore the potential impacts of envisaged technological developments in order to mitigate risks and inconveniences and optimise benefits as well as the chance of success/uptake of these technological developments.

- Reframe and update the concepts, meanings, and expectations arising from the deployment of ICTs. In particular, explore the "rebound" of technologies in society and how societal uptake creates new grounds for innovation.

This top-down driver lays out the action paths through the RRI aims and separately considers the impacts through the SSH. There is a clear demarcation of types of activity within silos of traditional disciplinary groupings. There is a distinct lack of linking such activity to practice which seems to contradict the overall H2O2O mission. 
Drivers, such as the three key examples described here, have a direct impact on advances in ICT application. These drivers affect attitudes and societal norms. Indeed, the amalgam of top-down, middle-out and bottom-up drivers leads to a complex situation where the attitude and behaviour of individual professionals and professional collectives are highly influential in the delivery of socially acceptable ICT. Therefore with each passing day ICT ethics becomes more important as it is that which steers all those involved in ICT in an ethical direction.

\title{
Linking research and practice
}

\author{
Single views are flawed \\ Life is grey not black and white - \\ Harmony spawns hope
}

ICT is a practical subject and so it is reasonable to expect related research should have a strong link to practice. In Europe, the European Parliament's support for the ethical and social consideration of ICT has increased with each research framework. Cross disciplinary projects are encouraged and in the latest framework improved links to practice are demanded. In June 2014, the U.S. House of Representatives approved Frontiers in Innovation, Research, Science, and Technology Act of 2014 otherwise known as FIRST Act of 2014. Funding for research at the National Science Foundation (NSF) is laid out by this Act. It drastically cut the funding for the social, behavioural, and economic sciences areas. The previous year the Act banned NSF from supporting political science work that did not meet very narrow criteria. These moves seem to stifle cross-disciplinarity and send out a clear message that technologists including those in ICT should focus on technological issues rather than wider impacts. This is a retrograde step. The reason why is clear from an interview for Computers and Society (Himma, 2009) when I said, "... we live in an interdisciplinary world, we use resources in an interdisciplinary way and we face issues, challenges and problems that require us to draw upon our interdisciplinary skills and experiences. ICT is just part of our world and as such demands to be treated in an interdisciplinary way. So the field must be interdisciplinary - it is this that has coloured the way in which we have operated the ETHICOMP conference series since 1995."

The reports of four EU funded research projects which included an ICT ethics perspective have been briefly reviewed. The projects were completed successfully under FP7 which was the European Union's Research and Innovation funding programme for 2007-2013. The four projects were: EGAIS (The Ethical GovernAnce of emergIng technologieS - New Governance Perspectives for Integrating Ethics into Technical Development Projects and Applications); EIW3R (The ethics of information warfare: risks, rights and responsibilities); ETICA (Ethical Issues of Emerging ICT Applications); and PHM-ETHICS (Personalized health monitoring - Interdisciplinary research to analyse the relationship between ethics, law and psychosocial as well as medical sciences). ETICA and PHM-ETHICS had a strong interdisciplinary flavour. The following direct quotes from the end of project reports provide a sense of project achievement.

EGAIS (2012) states, "Within EGAIS, we defined guidelines that could inform policymakers and researchers in planning, implementing and assessing the ethical governance of research both within research projects and in a broader policy context."

EIW3R (2013) states, "These research findings provided the conceptual ground for the identification of normative theories that could generate ethical principles of decision-making within the context of IW."

ETICA (2013) states, "Implementing these [ETICA] recommendations will contribute to better and ethically more sensitive processes of technology development. ... ETICA has made significant 
inroads in disseminating these findings and influencing policy and practice in ICT ethics, in particular on the European level."

PHM-ETHICS (2013) states, "The PHM-ETHICS project developed a methodology which can be used modularly for the assessment of various aspects regarding impact and features and impact of PHM technologies."

It appears that only ETICA has had some immediate impact beyond research through its involvement in policy making. This is a top-down driver influence. The other three projects seemed to conclude with potential impact claims providing explanations of what outputs could be used for. Overall, there are some general points which come out of this brief review. Links with practitioners appear tentative as the focus of these projects is weighted towards concepts and theory. However, some would argue that it is unreasonable to expect pragmatic outcomes from projects of 2 to 3 years' duration. If so then the purpose of such projects needs to be explored. From the four projects reviewed there was little evidence that projects had drawn from previously funded projects of others. If this is commonplace then research effort seems sporadic rather than catalytic or progressive. The value of such research needs to be questioned. If the focus of research is simply research and a tool for spawning the next funded project then its impact on the practical world of ICT at best will be very limited. The volume of published output from funded research is phenomenal, it is the classic information overload which, if left to fester, will mutate into information pollution which Nielsen(2003) argues, "stops being a burden and becomes an impediment to your ability to get your work done", in this case research.

\section{Educating future generations}

One way in which ICT ethics research can be linked to practice is through the education of future generations of ICT practitioners. Programmes, in terms of both curriculum and pedagogy, should be informed by research in such a way that the relevance of research is implicit and that education goes beyond the confines of the technology. This broadening of education is paramount in reducing the risk of unacceptable ICT. Denning (2001) argues that, "The problem is that IT's way of looking at itself is lopsided toward the technology and is therefore self-limiting. Approaching the design of software and services with customers at the center runs against the grain of our field. We need a major shift of world-view to cross that chasm." This lopsided view is epitomised by the concluding remarks of Meijer and Kapoor (2014), "Sooner than you think, every company will be a software company. The obvious way to run a software company is as a meta software application, recursively structured as a layer of commuting closed-loop feedback systems, using a strictly layered architecture modeled after the time-proven hierarchal structure of armies and applying softwareinspired profiling and debugging techniques to optimize the profitability of the enterprise." To conclude an article with jargon-ridden phraseology is unimpressive. The stated view is steeped in technology, has little regard for the environment in which an enterprise exists and appears to have no moral concern for society and its citizens.

Professional bodies often demand that ethical and social issues be included in programmes in order for accreditation to be achieved. It is important to consider how meaningful the coverage of ethics and social impact issues is in programmes. It is unacceptable if inclusion is more about compliance rather than a desire to include ethics and social impact because it is essential and relevant. Superficial compliance to achieve accreditation is unethical and therefore unprofessional.

There is an expectation by ICT undergraduates that they will be instructed in the theories, methodologies and application of ICT. They are usually unaware and therefore have no expectation that their university education must include the ethical and societal context within which ICT exists. These technologically-oriented students have a resonance with experiential learning. Consequently, any attempt to expose them to ethical and societal perspectives of IT is more likely to succeed if a varied diet of experiential learning is provided (see, for example, Essendal and Rogerson, 2011). 
Academic philosophers delivering lectures about the nuances of ethical theory is inappropriate and indeed is likely to strengthen the barriers behind which purist technologists will defend their technological ideology.

The opportunity to participate in an active rather than passive manner leads to an experiential journey of maturity from tutor-led activities to student-led activities. Through this process, ICT professionals of the future are more likely to gain the necessary skills and knowledge to act in a socially responsible manner not on the basis of instinct and anecdote but on rigour and justification. It is important to provide tools to support this broader approach. Research activity has led to several tools which can be used in programmes and subsequently taken into practice on graduation. Three exemplars are DIODE, FRRIICT and SoDIS.

DIODE is a structured meta-methodology for the ethical assessment of new and emerging technologies (Harris et al, 2011). DIODE was designed by a mixture of academics, governmental people and commercial practitioners. It was designed to help diverse organisations and individuals conduct ethical assessments of new and emerging technologies.

The Framework for Responsible Research and Innovation in ICT (FRRIICT, 2015) is a tool that helps those involved in research and innovation in ICT to do so responsibly. The Framework consists of a set of scaffolding questions that allow researchers, funders and other stakeholders to consider a range of aspects of ICT research.

The Software Development Impact Statement (SoDIS) process extends the concept of software risk in three ways: it moves beyond the limited approach of schedule, budget, and function; it adds qualitative elements; and it recognizes project stakeholders beyond those considered in typical risk analysis (Gotterbarn and Rogerson, 2005). SoDIS is a proactive feed-forward approach which enables the identification of risks in the manner in which ICT is developed and in ICT itself.

Based on my experience of the many students I have had the privilege to teach, I believe ICT professionals of the future do care about the impact they will have on society. There is the wherewithal to build fit-for-purpose ethically sound systems by design but it will still happen more by accident unless effective education underpinned by relevant research exists. This remains an ongoing challenge in providing a balanced diet in the curriculum which adequately covers both the technical and the non-technical.

\title{
Future vision and conclusions
}

\author{
Computer jargon \\ Academic rhetoric - \\ Actions not words count
}

When I first engaged with this community over 20 years ago I was struck by the open-mindedness of its members. It was a far cry from the single-minded, hierarchical culture that existed and still exists in some areas of academia. The core principles on which the ETHICOMP conference series is founded reflect this inclusive community. These principles are:

- It is a broad based conference series which address the social and ethical perspectives of ICT and converging technologies.

- It is inclusive providing a forum for those with diverse opinions to share and debate issues in a collegiate atmosphere. Dialogue is fundamental.

- It is multidisciplinary. This means that both single discipline and multidiscipline papers are presented at the conferences. The community is receptive of these differing perspectives 
- It is culturally diverse. Delegates have come from all continents and presented papers from many cultural perspectives.

- It is supportive of academic growth. New scholars and researchers are encouraged to present papers, all of which are within the main programme rather than in a separate stream. This promotes inclusivity and collegiality.

Many of those in the community exhibit common cognitive traits which can be summarised by Gardner's (2007) Five minds for the future classification described as:

- Disciplinary Mind: The mastery of specific scholarly disciplines, crafts or professions.

- Synthesizing Mind: The ability to integrate ideas from disparate sources into a coherent whole and to communicate that integration to others.

- Creating Mind: The capacity to break new ground through new ideas, unfamiliar questions and fresh ways of thinking.

- Respectful Mind: An awareness and appreciation of differences among human beings and human groups.

- Ethical Mind: The realisation of one's obligations as a worker and as a member of society.

This type of collective action and individual attitude should be cherished and nurtured for it holds the key to the future. Unfortunately, today within academia, there seems to be a growing trend to address the ethical and social implications in a single disciplinary manner. There is a dwindling dialogue between industry and academia about such matters. Within industry and government the compliance culture has taken a firm hold and so strangles the opportunity for dialogue and analysis of complex multi-faceted socio-ethical issues related to ICT. The gatekeepers of past generations who provided the glue between academia, industry and government are becoming increasingly inactive and a serious void now exists.

\section{Global Action Plan}

The global action plan called Future Vision is proposed as an initiative to address the serious fragmentation of work in and between academia and industry related to so-called ICT Ethics. We need to identify what and where progress has been made, what problems or barriers exist and where is the future potential. A number of actions are suggested to address this issue. Existing activity could be accumulated under these actions. The actions are as follows:

- Review projects (funded through, for example, FP7 and H2O20 in the European Union, NSF in the US, EPSRC and ESRC in the UK and ARC in Australia) with significant ethics-social impact content to ascertain:

○ the level of multi/inter/transdisciplinarity

- the level of engagement with industry, government and public sector services

- the post-project impact on the roll-out of acceptable ICT

- the key active individuals in the area of pragmatic ICT ethics

- Identify professional bodies, businesses and public bodies which have proactive initiatives to promote and sustain good practice. For example, in Europe, the Council of European Professional Informatics Societies (CEPIS, 2015) is currently strongly promoting ethical ICT practice as one of the four pillars of ICT professionalism.

- Identify other active individuals who fall outside professional bodies, businesses and public bodies but have potential contributions to make. These could offer rich alternative perspectives.

- From these surveys develop a new network of those in academia, industry, public sector, government who are active in the area. Such a network would be the catalyst in Future Vision. 
- Creative effective communication channels which will enable dialogue and collaboration across the network and beyond.

- Develop a new vision for ICT ethics which is theoretically grounded but pragmatic in action so that industry and government will engage, accept and embrace. ICT Ethics can be defined as integrating ICT and human values in such a way that ICT advances human values, rather than doing damage to them which therefore must include the formulation and justification of policies for the ethical use of ICT, and carefully considered, transparent and justified action leading to ethically acceptable ICT products and services (Rogerson, 2011).

- Make a difference through challenging complacency, indifference and ambivalence regarding ethical ICT by those involved in any aspect of researching, developing, implementing and using ICT.

The aim of Future Vision is to regenerate the relationships across the wider community so that ICT will be developed and utilised in an ethical and socially acceptable manner. It is not simply an academic initiative but a whole-world initiative which will lead to an improvement in practice. I and my generation are not the ones to drive this through. Future Vision is in the hands of the millennials.

\section{References}

Bennett, L. (2014), "Robot identity assurance", ITNOW, September, pp. 10-11.

Boyle, R. (2009), Public sector change management - looking back to look forward, Keynote address, Association of Chief Executives of State Agencies (ACESA) Conference, 1 October, presentation transcript available at: http://www.slideserve.com/allison/public-sector-change-managementlooking-back-to-look-forward (accessed 09/07/2015).

CEPIS (2015), Ethics, The Council of European Professional Informatics Societies, available at: https://www.cepis.org/index.jsp?p=940\&n=2849 (accessed 14 May 2015).

Dainow, B. (2014), "Ethics in emerging technology", ITNOW, September, pp. 16-18.

Denning P.J. (2001), "When IT becomes a profession" in Denning, P.J. (Editor), The Invisible Future: The Seamless Integration of Technology Into Everyday Life, McGraw-Hill pp. 295-325.

EGAIS (2012), EGAIS Report Summary, Publications Office of the European Union, available at: http://cordis.europa.eu/result/rcn/53898_en.html (accessed 28 April 2015).

EIW3R (2013), EIW3R Report Summary, Publications Office of the European Union, available at: http://cordis.europa.eu/result/rcn/59645_en.html (accessed 28 April 2015).

Ericsson ConsumerLab (2013), Young professionals at work, An Ericsson Consumer Insight Summary Report, April 2013, available at: http://www.ericsson.com/res/docs/2013/consumerlab/youngprofessionals-at-work.pdf (accessed 09/07/2015).

Essendal, T. and Rogerson, S. (2013), "A holistic approach to software engineering education", in Hussey, M., Wu, B. and Xu, X. (Editors), Software industry oriented education practice and curriculum development: experiences and lessons, IGI Global, Pennsylvania, USA, Ch 5 pp83-95.

ETICA (2013), ETICA Report Summary, Publications Office of the European Union, available at: http://cordis.europa.eu/result/rcn/54085_en.html (accessed 28 April 2015).

European Commission (2013), A guide to ICT-related activities in WP2014-15, available at: https://ec.europa.eu/programmes/horizon2020/sites/horizon2020/files/ICT\%2Oin\%2OH2020\%20 WP2014-15_0.pdf (accessed 28 April 2015).

European Commission (2014), How to Go about RRI and SSH in ICT-related parts of H2020 WP14, available at:

http://ec.europa.eu/information_society/newsroom/cf/dae/document.cfm?action=display\&doc id=4160 (accessed 29 May 2014).

Ferry, G. (2003), A Computer Called LEO: Lyons Tea Shops and the world's first office computer, Fourth Estate, London.

Freeland, A. (2014), "Cultural differences", ITNOW, September, pp. 24-25.

Frey, C.B. and Berger, T. (2104), "Work in the digital age", RSA Journal, Issue 3 2014, pp. 16-19. 
Gardner, H. (2007), Five minds for the future. Boston, MA: Harvard Business School Press.

Gotterbarn, D. and Rogerson, S. (2005), "Next generation software development: responsible risk analysis using SoDIS", Communications of the Association for Information Systems, Vol. 15, pp. 730-50.

Harris, I., Jennings, R.C., Pullinger, D., Rogerson, S. and Duquenoy, P. (2011), "Ethical Assessment of New Technologies: A Meta-Methodology", Journal of Information, Communication \& Ethics in Society, Vol. 9 No. 1, pp. 49-64.

Himma, K. (2009), "Simon Rogerson: making a difference 2005", ACM SIGCAS Computers and Society - Celebrating SIGCAS' 40th Anniversary - Interviews with Past SIGCAS Award Recipients, Vol 39 Issue 2, September, pp. 22-23.

Holt, A. (2014), "Flight control", ITNOW, September, pp. 26-27.

Meijer, E. and Kapoor, V. (2014), "The responsive enterprise: embracing the hacker way", Communications of the ACM, Vol. 57 No. 12, pp. 38-43.

Nielsen, J. (2003), quoted in Twist, J. "Web guru fights info pollution", BBC News Online, available at: http://news.bbc.co.uk/1/hi/technology/3171376.stm (accessed 29 April 2015).

PHM-ETHICS (2013), PHM-ETHICS Report Summary, Publications Office of the European Union, available at: http://cordis.europa.eu/result/rcn/56833_en.html (accessed 28 April 2015).

FRRIICT (2015), Framework for Responsible Research and Innovation in ICT, available at: http://responsible-innovation.org.uk/torrii/content/framework (accessed 30 April 2015).

Rogerson, S. (1995), "But IS IT ethical?", IDPM Journal, Vol. 5 No. 1, pp. 14-15.

Rogerson, S. (2004), "ETHIcol - Tag Ethics", IMIS Journal, Vol. 14 No. 5 October.

Rogerson, S. (2011), "Ethics and ICT", in Galliers, R. and Currie, W. (Editors) The Oxford Handbook on Management Information Systems: Critical Perspectives and New Directions, Oxford University Press, Oxford, Chpt 23, pp. 601-622.

Rogerson, S. (2014), "Preparing IT professionals of the future." Mondo Digitale, AICA - Associazione Italiana per I'Informatica ed il Calcolo Automatico, No 50. 2014(2). April, available at: http://mondodigitale.aicanet.net/2014-2/ (accessed 28 April 2015).

Rogerson, S. (2015), "Technological Dependency". ACM SIGCAS Computers and Society, forthcoming. Rogerson, S. and Bynum, T.W. (1995), "Cyberspace: The Ethical Frontier", The Times Higher Education Supplement, No 1179, 9 June, p. iv, available at: https://www.timeshighereducation.co.uk/features/cyberspace-the-ethical-frontier/98490.article (accessed 09/07/2015).

Runciman, B. (2014), "Drones, robots, ethical decision dilemmas", ITNOW, September, pp. 6-9.

Smith, M.L. (2011), "Limitations to building institutional trustworthiness through e-government: a comparative study of two e-services in Chile." Journal of Information Technology, Vol. 26, pp. 7893.

Southey, D. (2014), "What could happen?", ITNOW, September, pp. 14-15.

THES (1995), "Companies offered ethics advice”, Times Higher Education, 10 April.

Wang, F-Y., Carley, K.M., Zeng,D. and Mao W. (2007), "Social Computing: From Social Informatics to Social Intelligence", IEEE Intelligent Systems, Vol. 22 No. 2, pp. 79-83.

\section{About the author}

Simon Rogerson is Professor Emeritus in Computer Ethics and former Director of the Centre for Computing and Social Responsibility at De Montfort University, UK. Following a successful industrial career where he held managerial posts in the computer field, he now combines research, lecturing and consultancy in the management, organisational and ethical aspects of ICT. He gave up his fulltime post in September 2010 and now works part time. He has published over 300 academic papers and written 6 books. He conceived and co-directed the ETHICOMP conference series from 1995 to 2013. He received the 2000 IFIP Namur Award for outstanding contribution to the creation of awareness of the social implications of ICT. In 2005 he became the first non-American to be given the prestigious SIGCAS Making a Difference Award by the ACM. He was a Vice President and former 
Chairman of the Institute for the Management of Information Systems. He is editor of the Journal of Information, Communication \& Ethics in Society. He is a Fellow of BCS, The Chartered Institute of IT; a Fellow of Institute for the Management of Information Systems; and a Fellow of Royal Society for the encouragement of Arts, Manufactures and Commerce.

\section{Citation details}

ROGERSON, S. (2015) Future Vision, Special Issue - 20 years of ETHICOMP, Journal of Information, Communication and Ethics in Society, Volume 13, Issue 3/4, August 2015. 